\title{
Adenocarcinoma in Colonic Interposition
}

\author{
Shahar Grunner ${ }^{a, c}$ Hayim Gilshtein ${ }^{a} \quad$ Eliahu Kakiashvilia, b \\ Yoram Kluger ${ }^{a, b}$ \\ ${ }^{a}$ Department of General Surgery, and Divisions of ${ }^{b}$ Surgical Oncology and ${ }^{c}$ Trauma and \\ Acute Care Surgery, Rambam Health Care Campus, Haifa, Israel
}

\section{Key Words}

Colonic interposition · Colon adenocarcinoma · Interposed colectomy

\begin{abstract}
A 59-year-old female with dysphagia presented to our clinic. In childhood, she underwent colonic interposition due to anastomotic stricture after a previous proximal gastrectomy for gastric ulcer perforation. Imaging studies revealed a space-occupying lesion obstructing the distal interposed colon. At surgery, completion gastrectomy with segmental colectomy was carried out, and Roux-en-Y coloenterostomy and enteroenterostomy were performed.
\end{abstract}

\section{Introduction}

Colonic interposition is a procedure practiced for the management of both benign and malignant diseases of the esophagus. The left colon is preferred for the transposition due to its smaller diameter, but right colon or transverse colon interpositions are performed as well. Malignant tumor of the transposed colon is a rare long-term complication of the procedure and is related to the irritation of the colonic mucosa by gastric acid content or bile [1]. When encountered with this clinical occurrence, interposed colectomy is the procedure of choice. Gastric pull-up and anastomosis of the proximal esophagus via a right thoracotomy (Ivor Lewis procedure) substitutes the resected transposed colon.

Herein, we present a patient who was diagnosed with interposed colonic carcinoma at the level of the anastomosis to the remnant stomach. In a previous operation in early childhood, her transverse colon was used to substitute the esophagus due to benign stricture. The proximal stomach was removed in the index operation, precluding a gastric pull-up procedure. 


\section{Case Presentation}

A 59-year-old woman presented to our clinic complaining of difficulties in swallowing both solid food and clear fluids.

At the age of 3, proximal gastrectomy and pyloroplasty were performed due to peptic disease and perforation. After this surgery, she suffered from anastomotic stricture, which was treated with repeated dilatations. Due to persistent stricture, a long-segment transverse colon interposition was carried out 1 year later. Colon interposition was performed using the Ivor Lewis approach, with the colon being anastomosed to the proximal esophagus via a right thoracotomy.

Recently, the patient started to complain of dysphagia and experienced weight loss. Endoscopy revealed a large, ulcerated lesion obstructing the distal interposed colon. A biopsy specimen taken from the mass revealed adenocarcinoma of a colonic origin.

Computerized tomography of the chest and abdomen showed the same lesion in the distal interposed colon without distant metastases. A barium swallow revealed an apple core lesion in the intra-abdominal portion of the interposed colon at the level of the anastomosis to the remnant stomach (fig. 1). Colonoscopy was normal.

After adequate nutritional support, the patient was operated. At laparotomy, the tumor was found at the level of the anastomosis of the colon to the remnant stomach. The interposed colon was the transverse colon based on its main blood supply - the middle colic artery and vein. The colon was anastomosed to the remnant stomach at the level of the gastric antrum, but the remnant gastric antrum was too short for gastric pull-up. Considering the surgical anatomy discovered during the procedure, we decided to avoid reinterposition surgery, as this would have resulted in a very short remnant colon length. During surgery, the main branches of the middle colic vessels were isolated and preserved. Completion gastrectomy with segmental colectomy was carried out. The colon was dissected from the hiatus to enable resection in an adequate distance from the tumor.

Roux-en-Y coloenterostomy and enteroenterostomy were performed, and the patient recovered uneventfully. Pathology confirmed the diagnosis of colonic adenocarcinoma. The tumor measured $3.5 \mathrm{~cm}$ in diameter, but all 15 lymph nodes were negative for tumor cells (T3NO). The proximal margin of resection was $7 \mathrm{~cm}$ in length. No further oncological treatment was offered to the patient, and she was followed up in the outpatient clinic. At the 6-month follow-up, she was in good health without recurrent disease.

\section{Discussion}

Adenocarcinoma of the interposed colon is a rare occurrence [2]. Only scattered case reports describe this clinical entity [3-5]. The tumor probably develops from long-standing colonic mucosa irritation by gastric juice and bile. With regard to cologastric junction carcinoma, debate raises on whether these tumors should be considered colonic or gastric in nature.

As pathology showed that the tumor in our patient was of a colonic origin, we decided to manage it as adenocarcinoma of the colon. The short antral segment found during examination indicated the surgical procedure in our patient: surgical resection of the interposed colon with clear margins. Preservation of the middle artery and vein enabled preservation of the short colonic segment anastomosed to the esophagus in a previous surgery.

In cases of interposed colonic carcinoma, further oncological treatment is considered based on the TNM classification, and close postoperative follow-up is mandatory. 


\section{Case Reports in Oncology}

\begin{tabular}{l|l}
\hline Case Rep Oncol 2013;6:186-188 \\
\hline DOI: $\underline{10.1159 / 000350743}$ & $\begin{array}{l}\text { C 2013 S. Karger AG, Basel } \\
\text { www.karger.com/cro }\end{array}$ \\
\hline
\end{tabular}

Grunner et al.: Adenocarcinoma in Colonic Interposition

\section{Conclusion}

A high index of suspicion for colonic adenocarcinoma is needed in all patients who underwent colonic interposition due to the deleterious effect of long-standing mucosal irritation.

\section{References}

1 Kuwabara Y, Kimura M, Mitsui A, Ishiguro H, Tomoda K, Mori Y, Ogawa R, Harata K, Katada T, Fujii Y: Adenocarcinoma arising in a colonic interposition following a total gastrectomy: report of a case. Surg Today 2009;39:800-802.

-2 Houghton AD, Jourdan M, McColl I: Dukes A carcinoma after colonic interposition for oesophageal stricture. Gut 1989;30:880-881.

-3 Shersher DD, Hong E, Warren W, Penfield Faber L, Liptay MJ: Adenocarcinoma in a 40-year-old colonic interposition treated with Ivor Lewis esophagectomy and esophagogastric anastomosis. Ann Thorac Surg 2011:92:e113-e114.

-4 Lindahl H, Rintala R, Sariola H, Louhimo I: Long-term endoscopic and flow cytometric follow-up of colon interposition. J Pediatr Surg 1992;27:859-861.

5 Briel JW, Tamhankar AP, Hagen JA, et al: Prevalence and risk factors for ischemia, leak, and stricture of esophageal anastomosis: gastric pull-up versus colon interposition. J Am Coll Surg 2004;198:536-542.

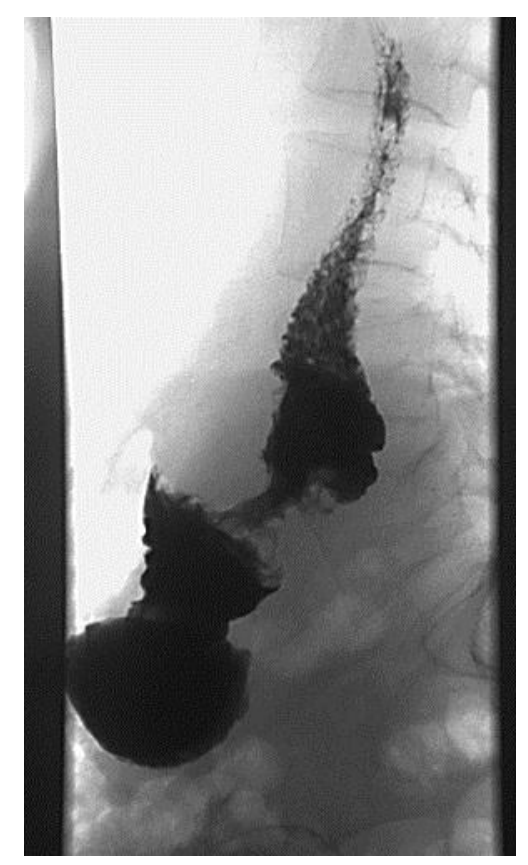

Fig. 1. A barium swallow demonstrating an apple core lesion at the lower part of the interposed colon. 